DOI: http://dx.doi.org/10.12957/demetra.2014.9558

\title{
Nutricionista em atenção básica: a visão do usuário
}

\section{Nutritionists in primary health care: the user's viewpoint}

Pauline Müller Pacheco ${ }^{1}$

Maurem Ramos²

' Departamento de Medicina Social. Programa de Pós-graduação em Epidemiologia. Universidade Federal do Rio Grande do Sul. Porto Alegre, RS, Brasil.

${ }^{2}$ Departamento de Medicina Social. Universidade Federal do Rio Grande do Sul. Porto Alegre, RS, Brasil.

Correspondência / Correspondence Pauline Müller Pacheco

Departamento de Medicina Social, Instituto de Psicologia. Universidade Federal do Rio Grande do Sul

Rua Ramiro Barcelos, 2600, sala 425 - Bairro

Santa Cecília

90035-003 Porto Alegre, RS, Brasil

E-mail: paulinempacheco@gmail.com

\section{Resumo}

Introdução: Este estudo tem por objetivo conhecer a percepção dos usuários do SUS sobre a atuação dos nutricionistas em atenção primária, identificar se o usuário reconhece este trabalho como importante para sua saúde e quais são suas expectativas em relação ao mesmo. Métodos: Foram realizadas entrevistas semiestruturadas individualmente com usuários de Unidades Básicas de Saúde, atendidos ou não pela nutricionista da unidade. As entrevistas foram transcritas e realizou-se análise textual discursiva. Resultados: O nutricionista foi corretamente associado a alimento, alimentação e nutrição; entretanto, os limites de sua atuação são tênues, apontando para uma fraca identidade profissional. O trabalho desenvolvido foi avaliado sempre positivamente e reconhecido como importante para a saúde dos usuários. As expectativas da prática apontam para a necessidade de um atendimento humanizado e integral, com mais ações voltadas para o coletivo - comunidade e trabalho em equipe -, concordando com as políticas de saúde vigentes. Conclusão: Sugere-se que, para alcançar as expectativas depositadas pelos usuários e avançar no processo de profissionalização, é necessário haver escuta e observação das demandas, reavaliando-se o processo de formação e o cotidiano da prática, com vistas aos novos paradigmas da atenção básica e da promoção da saúde.

Palavras-chave: Nutricionista. Atenção Primária à Saúde. Percepção. Participação do Paciente. Relações ProfissionalPaciente. 


\section{Abstract}

Introduction: This paper aims to know the perception of users in the Brazilian Unified Health System (SUS) about the role of nutritionists in primary health care, identifying if they recognize the importance of the nutritionist's work for their health, and verify their expectations in relation to it. Methods: Semi-structured individual interviews were applied to users of Primary Health Units, under follow up or otherwise with the unit nutritionist. The interviews were transcribed and submitted to a discursive textual analysis. Results: The nutritionist was correctly associated to food, feeding and nutrition, although the boundaries of their function are subtle, suggesting a weak professional identity. The work developed has always been positively evaluated and recognized as important for the users' health. The expectations related to the practice point to the need of humanized and integral care, including more actions for the collectivity - community and team work - in accordance with present health policies. Conclusions: To meet expectations and advance in the professionalization process it is necessary to listen and fulfill the demands, as well as assess the education process and daily practice, taking into account the new paradigms of primary care and health promotion.

Key words: Nutritionist. Primary Health Care. Perception. Patient Participation. Professional-Patient Relations.

\section{Introdução}

A atenção primária em saúde ganhou destaque na criação do Sistema Único de Saúde (SUS) em 1988, sendo considerada um avanço no campo da saúde para o país. Destacamos este nível de atenção como um importante fator para promoção e proteção da saúde, prevenção de agravos, diagnóstico, tratamento, reabilitação e manutenção da saúde, favorecendo ações de vigilância epidemiológica e sanitária, controle de vetores e educação em saúde. ${ }^{1}$ Este trabalho pretende trazer a visão do usuário do SUS sobre a atuação do profissional nutricionista na atenção primária.

Enfatizamos o importante papel do nutricionista no modelo tradicional e, atualmente, nos Núcleos de Atenção à Saúde da Família (NASF), visto que a alimentação e nutrição constituem direitos humanos fundamentais, como consta na Declaração Universal dos Direitos Humanos, e confirmam Ferreira e Magalhães: ${ }^{2}$ "[...] são requisitos básicos para a promoção e a proteção da saúde”. Em 2010, o Brasil inclui o direito à alimentação como direito social da população brasileira. ${ }^{3}$ 
De acordo com esses princípios, o Ministério da Saúde do Brasil assumiu o compromisso com a promoção da alimentação saudável, devido à intrincada situação nutricional da população brasileira, que passa por uma transição nutricional. Coexistem no país crescentes índices de obesidade e prevalência importante de situações carenciais, como a deficiência de vitamina A e anemia ferropriva, assim como situações de fome.

Em 1999, o Ministério da Saúde aprovou e em 2011 renovou a Política Nacional de Alimentação e Nutrição (PNAN), que dedica suas diretrizes à promoção da saúde nutricional, devendo o profissional nutricionista estar habilitado a transformar essas diretrizes em ações. ${ }^{4}$

Neste trabalho, vamos destacar a atuação do nutricionista na atenção básica em saúde, pelo olhar do usuário do SUS, que para Silva ${ }^{5}$ é mais que um consumidor dos serviços, é um cidadão, que pode mobilizar-se para conseguir o que quer e precisa, com origens e necessidades diversas. É necessário compreender sua diversidade e buscar neles, através de diagnósticos (individuais e coletivos), os objetivos e metas para as ações em saúde.

Os usuários do sistema de saúde têm papel essencial na construção e manutenção do próprio sistema. Constituem metade da representação nos Conselhos de Saúde - o controle social, onde o usuário escolhe diretamente os rumos da saúde na sua comunidade e nas demais esferas. ${ }^{6}$

Para Levy, ${ }^{7}$ que estudou a percepção de usuário e trabalhadores sobre o Programa de Agentes Comunitários de Saúde (PACS) em Bauru-SP, havia uma concordância entre a proposta do PACS e a práxis dos agentes comunitários - demonstrada pela fala e satisfação dos usuários. Nas considerações finais, é ressaltada a importância dessa avaliação pela perspectiva do agente e do usuário, considerando-se a construção coletiva do PACS.

Ramos e Lima ${ }^{8}$ abordaram a visão dos usuários sobre o acesso e acolhimento em uma unidade de saúde de Porto Alegre-RS, identificando elementos geradores de facilidades e dificuldades que influenciam a qualidade do atendimento. As autoras trazem a importância dos aspectos estudados para a qualificação do serviço de saúde pelo usuário, através de seu papel como protagonista do sistema de saúde, tendo impacto direto na melhoria da relação entre ele e o serviço. Demonstram que a identificação de profissionais competentes e confiança na equipe, quanto a experiência e capacidade, são fatores que exercem grande influência sobre a escolha do serviço de saúde.

Shimizu e Rosales,${ }^{9}$ em seu estudo, demonstram que as ações de prevenção e promoção da saúde e a relação profissionais-usuários foram avaliadas positivamente, enquanto o acesso aos serviços de saúde, aos medicamentos e aos profissionais foram avaliados negativamente. As ações desenvolvidas na unidade de saúde da família de Brasília não garantiram os princípios de integralidade, sendo necessário rever estratégias, principalmente as que incrementem a participação da comunidade. 
Na relação do usuário-nutricionista, podemos destacar diversos aspectos, ligados à percepção do usuário, que estão diretamente vinculados às questões de profissionalização. Bosii ${ }^{10}$ expõe a necessidade de que a sociedade reconheça o saber diferenciado dos membros da profissão trabalhados na sua formação. O usuário, no presente trabalho, pode ser considerado representante desta sociedade, e, portanto, é a partir da sua visão que se pode avaliar o reconhecimento de aspectos fundamentais da profissionalização do nutricionista.

Dessa forma, constata-se a importância de entender a concepção que os usuários têm sobre o papel do nutricionista na sua saúde.

\section{Processos metodologicos}

Trata-se de um estudo exploratório, de caráter qualitativo, que se caracteriza por ser capaz de incorporar a questão dos significados e da intencionalidade aos atos, às relações e às estruturas sociais, compreendendo a realidade social. ${ }^{11}$

A amostra constituiu-se de usuários da rede de atenção primária do município de Porto AlegreRS. Estes são oriundos de unidades de saúde com atuação de um nutricionista que concordaram em participar da pesquisa. Os sujeitos da pesquisa eram usuários diretos do serviço de nutrição (em atendimento ambulatorial ou participantes de grupos) e usuários indiretos (usuários que não são atendidos diretamente pelo profissional nutricionista, mas que são atendidos na UBS). A finalidade de abordar estes dois grupos era incluir uma visão mais abrangente do nutricionista, evitando um possível viés por dados oferecidos apenas por usuários com contato direto com o profissional.

A amostra foi determinada por critérios de exaustão - recorrência de pensamentos apresentados pelos atores. ${ }^{10}$ Para a coleta de dados, foram realizadas entrevistas de curta duração com utilização de questionário semiestruturado. Os aspectos abordados no roteiro de pesquisa foram: conhecimento sobre as atividades realizadas pelo nutricionista, importância ou relevância para sua saúde e da comunidade e expectativas em relação ao trabalho do profissional.

As entrevistas foram gravadas e degravadas, e o conteúdo foi transcrito. Os dados foram utilizados mediante a autorização dos entrevistados em Termo de Consentimento Livre e Esclarecido, de acordo com o Comitê de Ética em Pesquisa da Secretaria Municipal de Saúde de Porto Alegre, que aprovou o projeto sob o no 374/2009. Esta é a condição essencial para a utilização dos dados, respeitando-se a confidencialidade dos indivíduos.

Após a transcrição das entrevistas, estas foram transformadas em textos, nos quais foi utilizada a análise textual discursiva. ${ }^{12} \mathrm{O}$ exame de todas as informações permitiu a emergência de categorias analíticas, fruto do diálogo entre o modelo teórico e os dados. Para cada uma das categorias, na medida em que estas sofriam releituras e análises cíclicas, foi produzido um texto, buscando 
expressar o conjunto de significados presentes. Após, foi realizada uma análise compreensiva: a articulação da análise descritiva com a visão do referencial teórico e com a compreensão surgida a partir destes, surgindo aí o texto final.

\section{Resultados e discussão}

Foram entrevistados nove usuários. Predominou o sexo feminino, com idade entre 16 e 74 anos. A presença mais marcante das mulheres está de acordo com a ideia de que elas procuram mais os serviços de saúde. ${ }^{13}$ Três dos entrevistados não recebiam atendimento por nutricionista da atenção básica. Dos demais, cinco estavam em acompanhamento há pelo menos três meses e um havia tido sua primeira consulta há pouco tempo.

Foram delimitadas, a partir das informações coletadas, algumas categorias temáticas que serão apresentadas a seguir.

\section{O nutricionista e suas interfaces na perspectiva do usuário do SUS}

A categoria apresenta como o nutricionista é percebido pelo usuário: quem ele é, como ele é e as atividades que desenvolve.

Na busca por identificar como o usuário percebe o papel do nutricionista, verifica-se a concordância dos achados com os autores Ypiranga e Gil, ${ }^{14}$ que referem que o nutricionista: “[...] surge dentro do setor saúde, tendo como objeto de trabalho a alimentação do homem no seu plano individual ou coletivo." 14

Os entrevistados, usuários, foram unânimes quanto à natureza do trabalho do nutricionista estar relacionada ao alimento e à alimentação. Percebem-se essas evidências nas falas dos entrevistados:

[...] orientar a gente a se alimentar um pouco melhor [...] para ter uma boa alimentação [...] a nutricionista cuida da tua saúde, cuida da pessoa... (S1 - USUÁRIO INDIRETO).

Como observado no relato acima, além de tratar do cuidado alimentar e nutricional, o profissional também é reconhecido como aquele que tem influência na saúde dos usuários. Reforça S8: "Ela quer ajudar, quer manter a sua saúd".

A promoção da saúde é um dos princípios gerais da Política de Atenção Básica. ${ }^{15}$ Da mesma forma, a PNAN reforça que "a alimentação e a nutrição constituem requisitos básicos para a promoção e a proteção da saúde, possibilitando a afirmação plena do potencial de crescimento e desenvolvimento humano, com qualidade de vida e cidadania”. ${ }^{4}$ Assim, os profissionais 
nutricionistas dessas unidades são percebidos como agentes promotores de saúde, preconizados pelas políticas de saúde vigentes.

Entre as atividades e competências que os usuários relatam ser do nutricionista, está a ideia de ensinar. Nas entrevistas, aparece na forma de "reeducação alimentar" ou de "passar a ciência". No entanto, não parece claro se esta é apenas uma reprodução do discurso da nutricionista ou se realmente reflete a percepção dos usuários sobre um aprendizado de novas condutas alimentares, visto que a abordagem era sempre através de um plano alimentar, sem o relato da utilização de outras metodologias educativas: S1 ressalta que o nutricionista "fez uma dieta com reeducação alimentar, [...] dieta pra mim aprender a comer". E S8: "me deu uma orientação sobre a dieta, [...] me educou alimentar [alimentarmente]".

O conceito de "educação alimentar" está intimamente ligado à história das ações e políticas de alimentação no Brasil, sofrendo muitas mudanças ao longo do tempo. ${ }^{16 ; 17}$ Iniciou-se a partir da década de 1940, fundamentada no "mito da ignorância"17 da população de baixa renda em relação a sua alimentação, que seria o determinante fundamental da desnutrição. Novas perspectivas consolidaram a educação alimentar e nutricional crítica, baseada: “[...] nos princípios da pedagogia crítica dos conteúdos, de orientação marxista, considerando que a educação nutricional não é neutra, como também não pode seguir uma metodologia prefixada."17

No momento atual, com a vigência da PNAN, apresenta-se a educação alimentar e nutricional como um processo de diálogo entre profissionais de saúde e a população, com foco na autonomia e autocuidado, referenciando a realidade local e considerando que as desigualdades sociais interferem no direito humano à alimentação adequada (DHAA). ${ }^{4}$

De acordo com o exposto, a educação alimentar e nutricional não tem conceito consolidado, visto que deve ser uma construção coletiva, com o objetivo de mudança de comportamento num processo integrado à realidade da pessoa, família ou comunidade.

Enquanto a educação e reeducação alimentar e nutricional apareceram como dominantes nos discursos, o termo "dieta” também se fez presente. Já em 1986, Gil ${ }^{18}$ apontava que: “[...] o nutricionista não é apenas um técnico calculador de dietas e planejador de cardápios”. Assim, não deve ser visto dentro desta perspectiva simplista, uma vez que, de acordo com a mesma autora, o profissional formado em Nutrição busca os fenômenos em sua totalidade, tendo significativo papel e utilidade do nosso país.

Quando na definição do que é o trabalho do nutricionista ou na referência do mesmo tema em outros momentos da entrevista, o profissional foi erroneamente denominado com o nome de outras profissões. Afirmou S7: “[...] eu acho, que nutricionista já é como um trabalho praticamente, já é uma médica”. 
Aparentemente, o papel do nutricionista é corretamente associado ao seu campo do saber e ferramentas de trabalho; entretanto, os limites de sua atuação parecem tênues, não configurando uma identidade bem estabelecida para o usuário. O resultado vai ao encontro da afirmação de Banduk, Ruiz-Moreno e Batista: ${ }^{19}$

A existência da profissão do nutricionista no Brasil, há mais de sessenta anos, ainda não lhe garante uma identidade profissional claramente percebida pela sociedade brasileira.

A confusão entre as profissões de nutricionista e de médico deve-se possivelmente ao fato de o termo médico ser utilizado como referência para o que se denomina como profissional de saúde. Sendo a identidade do nutricionista pouco clara, as confusões surgem. Bosi ${ }^{10}$ coloca que, entre as semiprofissões, a Nutrição está entre as que não se tornarão uma profissão. Como a autora reconhece que o processo de profissionalização é dinâmico, pode-se observar o nutricionista numa ocupação aspirante à sombra de uma profissão dominante, que detém o monopólio de um grupo de conhecimentos já reconhecidos pela sociedade, os quais legitimam o domínio que exercem.

O nutricionista também foi citado como passível de realizar atividades de profissionais da área da psicologia e da educação física. Desta forma, mencionou S5: "Bom, assim eu acho que ela tem muito jeito para psicóloga. É, pelo jeito que ela conversa comigo, sabe? Acho que para psicologia também daria certo". E do mesmo modo expressou S6: "ela podia dar [ginástica], ao menos um treinamento, pra treinar a gente, podia dar umas dicas, né".

A relação estabelecida com a psicologia parece se dar porque as relações entre o homem e o alimento ultrapassam as questões biológicas, e o tratamento envolve a escuta dos problemas e a abertura para questões sociais e emocionais, que implica um cuidado mais integral, para além dos sintomas físicos. Conforme salientaram as entrevistadas S4 e S8, respectivamente: "Ela cuida de tudo, ela cuida o que te faz bem, por exemplo, o que te faz bem para tua saúde". E: "Ela quer ajudar, quer manter a sua saúde."

Para o documento do Ministério da Saúde que trata do cuidado integral de DCNT, ${ }^{6}$ o cuidado faz parte do viver e conviver do ser humano, e segundo Valla e Lacerda, ${ }^{20}$ " [...] refere-se a um agir de respeito e responsabilização, constituindo uma 'atitude interativa que inclui o envolvimento e o relacionamento entre as partes, compreendendo acolhimento, escuta do sujeito"”.

A associação com atividades dos profissionais da área da educação física pode estar ligada às orientações para a prática de atividade física por parte do nutricionista, como recomendação para uma vida saudável. Esta orientação é coerente com o preconizado na publicação Dez Passos para a Alimentação Saudável, que coloca como o passo dez a prática de atividade física regular. ${ }^{21}$ 
Este aspecto pauta questões de delimitação das atribuições das áreas de atuação e de conhecimento de cada profissão, bem como as limitações da composição das equipes de saúde. No caso, o nutricionista pode recomendar a prática de atividade física, mas não pode estabelecer os termos em que deve ser realizada, visto que isso compete ao profissional de Educação Física. Importante ressaltar que psicólogos e educadores físicos não compunham a equipe das unidades pesquisadas, embora aparentemente exista demanda para os mesmos. Dessa forma, todos os profissionais da unidade, e não apenas o nutricionista, recebem essas demandas e a resposta que dão a elas (algo que não pode ser adequadamente avaliado com esta pesquisa) pode constituir parte da confusão percebida nas falas encontradas.

Este trabalho também buscou identificar que características os usuários atribuem a sua atuação do nutricionista. Para a totalidade dos entrevistados, o nutricionista sempre foi qualificado positivamente. Confirmou S1: "Acho assim que o trabalho dela é excelente". E S5: "Mas eu gosto da pessoa, da maneira que ela trata os pacientes dela".

Foram destacadas habilidades pontuais, como entender resultados de exames ou realizar avaliação física e triagem. Igualmente o vínculo, que aparece de diversas formas como a empatia, o atendimento humanizado, o interesse, o cuidado e até mesmo a exigência. A empatia surgia como afinidade, ressaltada por S4:"E tudo isso assim, eu acho que as pessoas assim tem mais afinidade, eu acho que por isso ela acertou bem pra mim." O sentimento humano está presente na conduta do profissional, segundo S4: "Ela é bastante humana sabe, ela compreende o ser humano". Estabelece-se uma relação com a política de humanização, que tem entre os princípios norteadores a valorização da dimensão subjetiva e social em todas as práticas de atenção e gestão. ${ }^{22}$ É necessário destacar que essas demonstrações de vínculo não significam que todos os princípios da política são atendidos.

A valorização da dimensão subjetiva do cuidado é referida pelo usuário como a capacidade de vinculação do profissional e demonstração de interesse sincero por suas demandas. Como assegurou S4: "ela é bem interessada, [...] exigente também, ela se impõe”. Esses aspectos agregadores do vínculo profissional-usuário, a partir do qual há abertura maior para contato, escuta, compreensão e resolução de problemas no momento do diagnóstico e ao longo do tratamento nutricional, são ressaltados pelos sujeitos da pesquisa. Seundo confirmou S5:

Quando ela me chamou, ela abraça, ela beija a gente, ela conversa, ela te trata como se tu fosse uma amiga de muitos e muitos anos. E isso te deixa livre para agir e conversar com ela, e contar... abrir o que tu ta sentindo.

Denotam-se também a atenção dispensada, a compreensão por parte do nutricionista dos problemas expostos, a explicação oferecida nas orientações, seu entendimento e como o profissional responde às demandas dos usuários. Comentaram S5 e S8: "Ela te dá atenção, ela te explica o porquê, 
como fazer, o que ta certo, o que ta errado, como fazer a alimentação correta". E ainda: "Recebi muita atenção, [...] ela se preocupou muito com a gente, não teve pressa, então é muito importante".

O nutricionista também é valorizado pelo próprio fato de atuar na resolução dos problemas alimentares. É possível que o fenômeno seja provocado pela satisfação de uma demanda emergente em alimentação e nutrição.

Pautando as questões relativas às atividades desenvolvidas pelos nutricionistas, alguns dos usuários indiretos relataram desconhecer qualquer atividade: "Eu não sei que trabalho ela desenvolve, porque até então eu não consegui entrar ainda, consultar com a nutricionista, nem sei o que eles fazem" (S1). Entre as atividades citadas pelos demais entrevistados, estão os atendimentos individuais, acompanhamento das famílias do Programa Bolsa Família e o Programa NASCER, grupo de educação alimentar.

Quanto aos procedimentos adotados nos atendimentos individuais, relataram-se orientações para alimentação, aumento no consumo de água, redução da alimentação; realização de anamnese, realização de recordatório alimentar, realização de exames, aferição de dados antropométricos, orientação de atividade física com supervisão de outros profissionais ou não, uso de tabelas (não especificadas, assim como seu uso), orientação sobre alimentos ricos em calorias, orientação sobre alimentação de lactentes.

As modalidades de atendimento citadas nos remetem as cuidados clínicos individuais ou às ações de execução das políticas públicas. Há, porém, evidências de que esses usuários não percebem as atividades dos profissionais realizadas junto à comunidade, mesmo que essas sejam realizadas efetivamente. S4 declarou:

Olha, eu sei que a enfermagem tem, e se ela tem de repente tem também [...] sempre tem, vamos dizer assim, uma paciente sai, [...] e daí já entra outro, ela tem bastante atendimento. [...] E se ela faz, de repente ela faz na comunidade, quem sabe, eu não vou dizer que não.

A comunidade é um dos sujeitos de ação para a Matriz Ações de Alimentação e Nutrição na Atenção Básica, ${ }^{23}$ cujo principal propósito é: “[...] sistematizar e organizar as ações de alimentação e nutrição e do cuidado nutricional para integrarem o rol de ações de saúde desenvolvidas na atenção básica à saúde”. Por isso, constitui ferramenta importante para pensar as ações desenvolvidas por nutricionistas encontradas neste estudo. Na Matriz de Ações, quando se coloca a questão da atuação do nutricionista na atenção básica, diz-se, a respeito das suas responsabilidades:

[...] têm por objetivo central contribuir com o planejamento e a organização das ações de cuidado nutricional local, visando qualificar os serviços e melhorar a sua resolubilidade, atuando de forma efetiva sobre os determinantes dos agravos e problemas alimentares e nutricionais que acometem a população daquele território. ${ }^{23}$ 
O documento segue afirmando a importância do fortalecimento das ações dos nutricionistas para uma melhoria da qualidade de vida da população, promoção da saúde, promoção de segurança alimentar e nutricional (SAN) e do DHAA, envolvendo os três sujeitos das ações: o indivíduo, a família e a comunidade. Somam-se a isso a formação em serviço de profissionais e a articulação de estratégias junto aos equipamentos sociais de seu território.

O trabalho, sendo limitado às ações individuais e restrito ao espaço físico da unidade de saúde, ou em outras nas quais seja predominante, que é o único percebido pelos usuários, também terá seus resultados limitados a essa esfera. Esta forma parcial de trabalho - herança do modelo de saúde biologicista e individualista - pode resultar numa baixa resolubilidade dos problemas ligados à SAN e ao DHAA.

Ceccim $^{24}$ aponta para problemas na formação:

Um imaginário liberal-privatista atravessa o que se ensina sobre saúde desde a educação infantil até a pósgraduação das áreas clínicas em saúde, uma concepção marcada pela prática de consultório, pelo atendimento individual embasado na díade diagnóstico-prescrição, tendo a doença como referência e o curativismo biologicista como paradigma.

O desenvolvimento de um trabalho multiprofissional "pode contribuir para a efetividade das ações de nutrição, a partir da construção compartilhada de conhecimentos”. ${ }^{23}$ Entretanto, este trabalho não pode ser baseado apenas em articulação formal, burocrática - que na realidade dos serviços de saúde pode ser traduzida pelos mecanismos de referência e contrarreferência. As conexões da equipe devem começar já na formação, e os profissionais devem se envolver efetivamente com o trabalho que pretendem executar. ${ }^{23}$ Ferreira e Magalhães ${ }^{2}$ concordam, apresentando entre os desafios da prática do nutricionista social a superação do modelo de formação profissional, gerador de práticas convencionais e fragmentadas, as quais se refletem num trabalho de equipe também fragmentado.

Assim, pode-se compreender que os modos de atuação profissional estão intimamente ligados ao paradigma que sustenta sua formação, o que na contemporaneidade vem sendo questionado, apresentando a necessidade de buscar um redimensionamento nos diferentes âmbitos: do conhecimento e formação e da prática.

\section{Importância do nutricionista em atenção primária}

A matriz de ações de alimentação e nutrição na atenção básica de saúde apresenta a ideia da importância do tema na prática dos profissionais: 
A atual situação epidemiológica brasileira representada pela dupla carga de doenças é razão que justifica a incorporação das ações de alimentação e nutrição no contexto da Atenção Primária em Saúde em geral e, em particular, da Estratégia da Saúde da Família. ${ }^{23}$

No contexto abordado na presente pesquisa, o nutricionista teve fundamental importância, de acordo com todos os entrevistados, embora alguns não consigam explicitar suas razões. Argumentou S9: "Eu acho que é importante ter uma nutricionista. [...] faz diferença sim ter uma nutricionista no posto." E ainda, o fato de não realizar atendimento com a nutricionista não representou fator impeditivo para que o usuário emitisse sua opinião sobre a importância do profissional na unidade.

Uma das razões apontadas foi que o nutricionista oferece um suporte, dá orientações específicas e diferenciadas. Afirmaram ter recebido informações que não obtiveram por outros meios, e quando questionados sobre o que pensavam sobre a unidade de saúde não contar mais com nutricionista, os relatos foram unânimes em salientar que seria uma grande perda para a comunidade.

S1 assim comentou: "Eu aprendi com [nome do nutricionista] coisas que eu não tinha aprendido em lugar nenhum entendeu”. E S8 acrescentou: "daí então eu nunca ia ter aquela orientação, ia voltar a comer de tudo que não podia.[...] se não estiver aqui eu vou pedir orientação para quem?”

Denota-se que os usuários percebem que as atividades e competências dos nutricionistas não podem ser assumidas pelos demais profissionais de saúde da unidade. Mesmo frente à confusão dos limites profissionais anteriormente relatadas, parece que o campo de saber da Nutrição e suas ferramentas de trabalho se sobrepõem, sugerindo que os usuários consideram as atividades do nutricionista intransferíveis. Isso diz respeito à especificidade do conhecimento.

A sociologia das profissões, segundo Bosi, ${ }^{10}$ considera que os conhecimentos e habilidades de determinada profissão devem convencer a sociedade de que os membros desta profissão: “[...] são possuidores de um saber diferenciado do que caracteriza os que não seguiram o mesmo treinamento", o que torna a base cognitiva da profissão favorável à profissionalização. Assim, embora, como já constatado anteriormente, haja uma fraca identidade profissional do nutricionista, pode-se observar que os resultados deste trabalho apresentam evidências favoráveis ao processo de profissionalização.

Foi citada a importância da presença do nutricionista, tendo em vista as pessoas que já estavam em tratamento, ou as que viessem a manifestar a demanda pelo profissional. Esses indivíduos perderiam suporte e aí se encontraria o aspecto negativo de não contar mais com o profissional nutricionista na unidade. Percebeu-se no depoimento de S4: "Ela vai fazer falta sim, as pessoas vão sentir falta dela”. 
Em relação a este aspecto, foi relatado que alguns não sentiriam diferença, não porque o tratamento não houvesse sido relevante, mas porque a base da mudança de comportamento alimentar e os conhecimentos para ela já haviam sido alcançados. Este resultado pode refletir o alcance da autonomia do usuário em relação a seu tratamento.

Por outro lado, a importância do profissional nutricionista foi ressaltada em função de problemas de saúde ou doenças específicas presentes na comunidade que justificam a presença do nutricionista na unidade. Argumentou S6: "É importante para a comunidade né, porque tem muitas pessoas obesas."

Isso pode ser traduzido, da mesma forma que foi abordado anteriormente, como a população sente que não disporia de suporte para resolução de problemas referente a doenças e agravos ligados a questões relativas à alimentação - esta é uma competência e habilidade específica do nutricionista.

A importância da presença de profissionais da nutrição na atenção básica em saúde parece ser reconhecida pela sociedade, de acordo com os achados nesta pesquisa. Este é um argumento a mais para a inserção progressiva do cuidado nutricional na atenção primária, já é prevista na Matriz de Ações de Alimentação e Nutrição na Atenção Básica de Saúde. ${ }^{23}$ Nesse mesmo documento, ainda é argumentado que:

A atuação do nutricionista em grande parte dos municípios brasileiros, precisa ser fortalecida para que a potencialidade do conhecimento da Nutrição e das intervenções neste campo possam, de forma efetiva, contribuir para a melhoria da qualidade de vida e de saúde da população.

Percebe-se que a situação emergente vem traçando um caminho em que a real necessidade de profissionais habilitados para trabalhar a questão da alimentação na atenção básica - de forma integral, humanizada e interdisciplinar - concorda com as políticas de saúde vigentes, atentando para a inclusão dos profissionais e o cumprimento das ações propostas nessas políticas.

\section{Expectativas da prática social do nutricionista}

As expectativas em relação à atuação do nutricionista mencionadas pelos usuários disseram respeito às ações a serem desenvolvidas e às formas de conduta no cuidado nutricional.

Em relação à conduta no cuidado nutricional, paciência e acolhida das ansiedades foram consideradas fundamentais na relação profissional-usuário. A paciência não significou, aparentemente, indulgência com as recaídas no tratamento. Diversos usuários afirmaram a 
importância da cobrança, da "rigorosidade", que pode se traduzir na importância do suporte continente na valorização dos resultados alcançados pelo paciente que o nutricionista está "investindo".

Outros aspectos, como comprometimento e coerência, foram abordados. Argumentaram S2: "Tem que se levar muito a sério, não é chegar [...] simplesmente passando uma dieta”; e S9: "é saber tratar essas pessoas mais pobres né, [...] saber falar o que a pessoa vai entender, não falar termos mais difíceis, saber falar assim [...] como se fosse igual àquelas pessoas".

A importância da avaliação dos custos da alimentação e da disponibilidade financeira para a elaboração de orientações coerentes para o tratamento foi levantada por vários usuários. Assegurou um usuário:

Ela foi excelente, eu gostei muito dela porque ela, [...] Primeiro analisou as condições financeira [...] A dieta, de acordo com as minhas condições financeiras e também de acordo com o meu organismo. (S2)

A competência técnica foi abordada de formas diferenciadas. Por um lado, o conhecimento técnico era reconhecido como necessário para que o nutricionista atuasse como agente de transformação através da educação, afirmou S3: "Ela tá usando toda ciência, tudo que ela estudou para passar para eles né, pra poder ajudar." Por outro, o fazer técnico pode representar um fator negativo para o estabelecimento de uma boa relação entre o usuário e o profissional, como observou S8: "se ela quisesse saber de levantar a voz, ou não quisesse aceitar, eu já via que ela não era uma pessoa que tinha tanto interesse pela gente, pelo tratamento, né. Ela queria ir pelo estudo dela, né, não queria aceitar palpite de outros."

Pode-se deduzir que a competência técnica é reconhecida como essencial e é uma das características esperadas de um bom profissional - isso sem que atrapalhe o espaço de escuta ou interfira na participação do usuário do serviço de atenção básica na escolha do seu próprio tratamento, comprometendo assim sua autonomia.

Outro tema levantado foi o valor atribuído à motivação. Assim se manifestou S7: “[...] estimular bastante a pessoa para a pessoa ir e voltar sempre, e fazer da nutrição [...] uma coisa prazerosa, uma coisa que dá vontade de vir sempre." A elevação da autoestima é outro modo como a questão da motivação surge nas falas. Os fatores de estímulo não foram listados, mas pode-se entender que todos os aspectos anteriormente abordados como esperados da conduta do nutricionista são motivadores da adesão ao tratamento, por criarem e reforçarem o vínculo profissional-usuário.

Deduzimos que a percepção dos usuários sobre a ação do nutricionista está restrita ao atendimento individual, o que pode ser reflexo da forma como os serviços de saúde estão 
organizados. A abordagem de grupo na perspectiva do usuário facilitaria o processo de aprendizagem e apropriação de outras formas de cuidar da saúde, conforme argumentou S7:

A atividade de grupo vai ajudar: "precisa caminhar, vai caminhar sozinha", essas coisas. Aí junta as pessoas e pelo menos em um certo horário praticar uma atividade. Com todos junto, reunidos, então vai todo mundo acompanhado, todo mundo junto, com esse objetivo. (S7)

A atividade de grupo foi levantada como uma alternativa para ações no âmbito da unidade de saúde, tanto em se tratando do aspecto educacional ou de informação, quanto de atividades de convivência. Citando S2 e S8, respectivamente:

Eu acho que o posto de saúde, ele deveria fazer [...] as pessoas que estão pouco acima do peso, não esperar que a pessoa vá procurar [...] aconselhar, fazer palestras, conversar com o pessoal. (S2)

Podia ter uma reunião com todas as pessoas que nem eu assim que tem esses problemas, [...] um debate ali e tal, se ela tem tempo, disposição para acompanhar a gente numa atividade assim, reunir tantas pessoas e fazer, uma vez por mês, atividade de uma hora, uma hora e meia mais ou menos. [...] e era nutrição né, passasse um filme, que fosse importante né. (S8)

O assunto "grupo" não emergiu somente como tema relacionado ao usuário, visto que despontou a ideia de o nutricionista envolver a equipe de saúde, seu próprio grupo de trabalho em atividades sobre alimentação e nutrição. A fala de S5 sustenta esse pensamento: "a alimentação dos colegas, orientá-los como se alimentar melhor, como fazer uma comida saudável”.

O valor do trabalho com a equipe justifica-se de diversas formas. Primeiramente, pela necessidade de educação permanente da equipe para os temas de SAN. Segundo, por oferecer ferramentas para a qualidade de vida, e por isso melhorar a saúde do trabalhador. E por fim, pela possibilidade de viabilizar um espaço onde a equipe possa trocar experiências, criar em conjunto e reafirmar seus próprios vínculos.

Sobre as atividades junto à comunidade fora da área física da unidade de saúde, essas são igualmente consideradas estranhas para os entrevistados. Nenhum dos usuários, diretos ou indiretos, sabia citar alguma atividade com esses critérios desenvolvida pelo nutricionista. Alguns citam esse tipo de atividade como "voluntariado" ou que dizia respeito "à vida pessoal" do nutricionista, e dessa forma demonstram não perceber como parte da prática profissional na atenção básica o desenvolvimento de ações junto à comunidade. Ao mesmo tempo, referem que há demanda de trabalho mais abrangente, como argumentou S2: 
[...] eles deveriam, estar mais junto da comunidade, nas casas ver a situação [...] tem gente que alimenta mal a criançada, na comunidade carente, ir lá ver como está a situação, como é que está a alimentação dessas crianças, não só se preocupar com o obeso [...] falta de orientação das famílias, das mães, dos pais que alimentarem corretamente seus filhos. (S2)

Outros usuários indicaram igualmente a importância do trabalho com crianças, citando a escola como espaço privilegiado para a realização das atividades. Confirmou S5: "poderia, acho que, por exemplo, passar nas escolas a alimentação adequada. [...] faria um bom trabalho dando orientação alimentar para as crianças." O entrevistado S1 afirmou ainda que o trabalho desenvolvido junto às crianças pode ser estendido aos pais: "Eu acho que uma coisa que ela poderia era visitar as escolas, dar orientação para os alunos, de repente os alunos levam para os pais".

Outro espaço citado foram as casas de cuidados para idosos, pela dificuldade de acesso à unidade de saúde. Da mesma forma que esses idosos não conseguem chegar à unidade, os entrevistados afirmam que parte da comunidade também não procura o serviço de saúde, por desinteresse ou porque desconhece o trabalho da nutrição. Portanto, o trabalho fora da unidade de saúde facilitaria a aproximação, viabilizando maior abrangência e o caráter preventivo das ações. O entrevistado S9 expressou esse juízo:

[...] poderia fazer alguma coisa por eles lá no meio da comunidade, porque aqui é difícil. Para as pessoas de baixa renda mesmo [...] é uma área que não é muito procurada. Então é mais fácil eles procurarem um clínico geral que procurar a nutricionista.

O tipo de atividade sugerida variou entre atividades educativas, tal como expressou S9:

[...] poderia dar essa orientação assim pra pessoas [...], podia fazer tipo palestras com o povo. [...] Mas tem que ir mesmo atrás do povo, não fazer eles virem até o posto porque eles não vão vir, eu acho. [...] através de associações que devem ter no meio das comunidades. (S9)

Dentro da proposta de atividades educativas, S6 ainda propôs:

Eu acho que ela devia é ir para a cozinha [...] ensinar como a gente cozinha nossa própria comida entendeu. [...] qualquer nutricionista que um dia desse umas aulas para nós, eu acho que isso seria bem aceito pelo povo, pela comunidade aqui. (S6) 
Atividades recreativas e de convivência foram trazidas, e S8 manifestou isso na assertiva: “[...] fazer um piquenique lá, pra gente passar um tempo lá conversando, se divertindo e contando alguma coisa, e vemos... Fazer uma caminhada junto".

Vale relembrar aqui que a comunidade - um dos três sujeitos de abordagem da Matriz de Ações $^{23}$ - deve ser vista como mais que um somatório de pessoas, como um sujeito coletivo, cujas ações executadas permitem "[...] consonância com o olhar e a estratégia de cuidado pretendidas com a construção de um novo modelo de atenção à saúde", ${ }^{23}$ o qual tem por base a atenção básica de saúde. Essas ações têm o potencial de dar maior resolubilidade à atenção à saúde, promovendo integralidade ${ }^{23} \mathrm{e}$, mais do que isso, se coordenadas às ações de vigilância em saúde terão impacto no perfil epidemiológico da população brasileira.

Foi expresso que o nutricionista poderia colaborar com problemas maiores da comunidade, como porta-voz junto aos órgãos do governo. S3 verbalizou: "[...] aí teria que entrar a prefeitura né, para ajudar. Porque sozinha ela não ia conseguir, teria que ter verbas pra isso [...] ela poderia representar a comunidade".

Este pode ser o sintoma da falta de uma liderança da comunidade, fraca participação no controle social ou mesmo a falta da estrutura do Conselho de Saúde, o que faz o usuário buscar no profissional com o qual se identifica, um porta-voz para suas demandas. Essa perspectiva vai contra a questão da autonomia do usuário para as decisões em saúde. Buss e Ferreira ${ }^{25}$ colocam que a promoção da saúde foi se ampliando a partir do estabelecido na Primeira Conferência, com novos elementos como a "promoção da responsabilidade social com o 'empoderamento' da população".

Como profissional da atenção básica em saúde, o nutricionista tem a premissa de buscar promover saúde, além do estímulo à alimentação saudável, trabalhar de acordo com seus demais princípios, inclusive estimulando protagonismo através da educação em saúde. Buss ${ }^{26}$ aponta para o empoderamento - ou empowerment - da população organizada como central na estratégia de promoção da saúde para reivindicação de políticas públicas saudáveis, sendo: "[...] uma condição indispensável para a viabilidade e efetividade das políticas públicas.”

O papel da educação em saúde é apontado como mais do que desenvolvimento de conhecimentos, mas como condutor de comportamento e atitudes, entre eles o estímulo da participação comunitária em decisões de saúde. ${ }^{27}$ Importante ressaltar que a educação em saúde para esses propósitos depende da superação das práticas convencionais e fragmentadas, como apontado por Ferreira e Magalhães, ${ }^{2}$ para perceber a necessidade do coletivo e assim promover seu protagonismo. 


\section{Conclusão}

Faz-se necessário estabelecer que os resultados deste estudo não têm a pretensão da generalização por seu caráter qualitativo - e não epidemiológico. Ele fornece ferramentas para pensar sob um novo ponto de vista (do usuário), como estão sendo percebidas as práticas dos nutricionistas em atenção básica.

A resposta da revisão bibliográfica deste estudo mostrou a fragilidade da posse de dados armazenados, até o presente momento, sobre a percepção do usuário do SUS de forma geral e especificamente em Porto Alegre-RS, em relação à atuação do nutricionista em atenção primária.

As respostas da pesquisa aplicada, no entanto, mostraram que há reconhecimento do nutricionista em atenção primária como profissional da área da alimentação e nutrição, exercendo influência positiva na saúde dos sujeitos participantes do estudo. Ainda que o nutricionista seja reconhecido dentro do núcleo de suas competências, os limites de sua atuação parecem tênues, demonstrando uma identidade pouco clara. Assim, é necessário conhecer e pensar como se desenvolve o processo de profissionalização, considerando a necessidade de transformações na formação e na prática, colocando-as a favor do reconhecimento profissional da categoria.

Os achados demonstram o trabalho do nutricionista muito voltado para ações no nível individual e restrito aos limites físicos da unidade de saúde, modo de atuação que parece estar intimamente ligado a uma formação também fragmentada e biologicista, que por sua vez dificulta ações no plano da equipe. Este constitui outro dos desafios da prática profissional: um trabalho em equipe, presente nas bases da formação e que reflita práticas mais integrativas junto à comunidade e a família, fortalecendo processos grupais e coletivos para a promoção da saúde e o desenvolvimento do protagonismo da comunidade.

O nutricionista sempre foi conceituado positivamente - possivelmente devido a questões ligadas ao vínculo em seus diversos aspectos - e teve fundamental importância, de acordo com todos os entrevistados - o que se justificativa pelo oferecimento de um suporte e de orientações específicas e diferenciadas. Esta última é também característica favorável ao processo de profissionalização e consoante as orientações do Departamento de Atenção Básica de Saúde do Ministério da Saúde.

As expectativas expressas pelos sujeitos de pesquisa formaram um arcabouço de preciosas indicações sobre o que é importante ser oferecido à comunidade nesse momento e como aquelas pessoas esperam ser tratadas. Constituem um conjunto de ferramentas que pode apoiar o nutricionista na sua meta fundamental de promover saúde a sua população de referência e reforçar a importância de um espaço permanente para escuta do usuário. 
A fim de se obter um quadro mais abrangente a respeito da percepção do usuário de atenção básica sobre o nutricionista, mais estudos devem ser realizados, considerando-se a escassa literatura sobre assunto da profissionalização do nutricionista, em especial no campo da Saúde Coletiva e sob a ótica do usuário.

\section{Referências}

1. Oliveira DC, Sá CP, Gomes AMT, Ramos RS, Pereira NA, Santos WCR. A política pública de saúde brasileira: representação e memória social de profissionais. Cad. Saúde Pública 2008; 24(1):197-206.

2. Ferreira VA, Magalhães R. Nutrição e promoção da saúde: perspectivas atuais. Cad. Saúde Pública 2007; 23(7):1674-1681.

3. Brasil. Emenda Constitucional n ${ }^{\circ} 64$, de 4 de fevereiro de 2010. Altera o art. $6^{\circ}$ da Constituição Federal, para introduzir a alimentação como direito social. Diário Oficial da União 4 fev. 2010.

4. Brasil. Ministério da Saúde. Política nacional de alimentação e nutrição. Brasília: MS; 2003.

5. Silva GGA, Egydio MVRM, Souza MC. Algumas considerações sobre o controle social no SUS: usuários ou consumidores? Saúde em Debate 1999; 23(53):37-42.

6. Brasil. Ministério da Saúde. Diretrizes e recomendações para o cuidado integral de doenças crônicas não-transmissíveis: promoção da saúde, vigilância, prevenção e assistência. Brasília: Ministério da Saúde, 2008.

7. Levy FM, Matos PE, Tomita NE. Programa de agentes comunitários de saúde: a percepção de usuários e trabalhadores da saúde. Cad. Saúde Pública 2004; 20(1):197-203.

8. Ramos DD, Lima MAD. Acesso e acolhimento aos usuários em uma unidade de saúde de Porto Alegre, Rio grande do Sul, Brasil. Cad. Saúde Pública 2003; 19(1):27-34.

9. Shimizu HE, Rosales C. Family perspective on a family care program. Rev. Latino-Am. Enfermagem 2008; 16(5):883-8.

10. Bosi MLM. Profissionalização e conhecimento: a nutrição em questão. São Paulo: Hucitec; 1996.

11. Minayo MC. O desafio do conhecimento: pesquisa qualitativa em saúde. 8. ed. São Paulo: Hucitec; 2004.

12. Moraes R. Uma tempestade de luz: a compreensão possibilitada pela análise textual discursiva. Ciênc. Educ 2003; 9(2):191-211.

13. Pinheiro RS, Viacava F, Travassos C, Brito AS. Gênero, morbidade, acesso e utilização de serviços de saúde no Brasil. Ciênc. Saúde Coletiva 2002; 7(4):687-707.

14. Ypiranga L, Gil MF. Formação profissional do nutricionista: por que mudar? Seminário Nacional Sobre Ensino de Nutrição; 1989; Goiânia. p. 19-36.

15. Brasil. Ministério da Saúde. Política nacional de atenção básica. Brasília: Ministério da Saúde; 2006. 
16. Lima ES. Gênese e constituição da educação alimentar: uma síntese. Physis: Rev. Saúde Coletiva 1997; 7(2):9-29.

17. Santos LA. Educação alimentar e nutricional no contexto da promoção de práticas alimentares saudáveis. Rev. Nutr. 2005; 18(5): 681-692.

18. Gil M. Recursos humanos em nutrição no Brasil: nutricionistas. Cad. Saúde Pública 1986;2(4):561-569.

19. Banduk MLS, Ruiz-Moreno L, Batista NA. A construção da identidade profissional na graduação do nutricionista. Interface 2009; 13(28):111-120.

20. Valla VV, Lacerda, A. As propostas terapêuticas de cuidado integral à saúde como proposta para aliviar o sofrimento. In: Pinheiro R; Mattos RD, organizador. Cuidado: as fronteiras da integralidade. Rio de Janeiro: Hucitec; 2004. p. 91-103.

21. Brasil. Ministério da Saúde. 10 passos para uma alimentação saudável para pessoas adultas. Brasília: Ministério da Saúde; 2007.

22. Brasil. Ministério da Saúde. Humaniza-SUS: Política Nacional de Humanização. Brasília: Ministério da Saúde; 2004.

23. Brasil. Ministério da Saúde. Matriz de ações de alimentação e nutrição na atenção básica de saúde. Brasília: Ministério da Saúde; 2009.

24. Ceccim RB, Armani TB, Oliveira DLLC, Bilibio, LF, Moraes M, Santos ND. Imaginários da formação em saúde no Brasil e os horizontes da regulação em saúde suplementar. Ciênc. Saúde Coletiva 2008; 13(5):1413-8123.

25. Buss PM, Ferreira JR. Atenção primária e promoção da saúde. In: Brasil. Ministério da Saúde. Projeto promoção da saúde. Brasília: Ministério da Saúde; 2001. p. 7-14.

26. Buss PM. Trabalho e subjetividade: cargas e sofrimento na prática da nutrição social. Rev. Nutr. 2000; 13(2):107-115.

27. Lopes EM, Anjos SJSB, Pinheiro AKB. Tendência das ações de educação em saúde realizadas por enfermeiros no Brasil. Rev. Enferm. 2009; 17(2):273-277.

Recebido: 23/2/2014

Revisado: $31 / 5 / 2014$

Aprovado: 30/7/2014 
